\title{
The effects of long-term noninvasive ventilation in hypercapnic COPD patients: a randomized controlled pilot study
}

This article was published in the following Dove Press journal: International Journal of COPD

17 November 201।

Number of times this article has been viewed

\author{
L De Backer' \\ W Vos ${ }^{2}$ \\ B Dieriks' \\ D Daems' \\ S Verhulst' \\ SVinchurkar ${ }^{2}$ \\ K Ides' \\ J De Backer ${ }^{2}$ \\ P Germonpre' \\ W De Backer'
}

'Antwerp University Hospital, Department of Respiratory Medicine, ${ }^{2}$ FluidDa, Antwerp, Belgium

Correspondence: Lieve De Backer Department of Respiratory Medicine, Antwerp University Hospital, Wilrijkstraat I0, 2650 Edegem, Antwerp, Belgium

Tel +3238213447

Fax +3238214447

Email lieve.debacker@ua.ac.be
Introduction: Noninvasive ventilation (NIV) is a well-established treatment for acuteon-chronic respiratory failure in hypercapnic COPD patients. Less is known about the effects of a long-term treatment with NIV in hypercapnic COPD patients and about the factors that may predict response in terms of improved oxygenation and lowered $\mathrm{CO}_{2}$ retention.

Methods: In this study, we randomized 15 patients to a routine pharmacological treatment $\left(\mathrm{n}=5\right.$, age 66 [standard deviation \pm 6 ] years, $\mathrm{FEV}_{1} 30.5[ \pm 5.1] \%$ pred, $\mathrm{PaO}_{2} 65[ \pm 6] \mathrm{mmHg}$, $\mathrm{PaCO}_{2} 52.4[ \pm 6.0] \mathrm{mmHg}$ ) or to a routine treatment and NIV (using the Synchrony BiPAP device [Respironics, Inc, Murrsville, PA] $)\left(n=10\right.$, age $65[ \pm 7]$ years, $\mathrm{FEV}_{1} 29.5[ \pm 9.0] \%$ pred, $\mathrm{PaO}_{2}$ $59[ \pm 13] \mathrm{mmHg}, \mathrm{PaCO}_{2} 55.4[ \pm 7.7] \mathrm{mmHg}$ ) for 6 months. We looked at arterial blood gasses, lung function parameters and performed a low-dose computed tomography of the thorax, which was later used for segmentation (providing lobe and airway volumes, iVlobe and iVaw) and post-processing with computer methods (providing airway resistance, iRaw) giving overall a functional image of the separate airways and lobes.

Results: In both groups there was a nonsignificant change in $\mathrm{FEV}_{1}$ (NIV group 29.5 [9.0] to 38.5 [14.6] \%pred, control group 30.5 [5.1] to 36.8 [8.7] $\mathrm{mmHg}$ ). $\mathrm{PaCO}_{2}$ dropped significantly only in the NIV group (NIV: 55.4 [7.7] $\rightarrow 44.5$ [4.70], $P=0.0076$; control: 52.4 [6.0] $\rightarrow 47.6$ [8.2], NS). Patients actively treated with NIV developed a more inhomogeneous redistribution of mass flow than control patients. Subsequent analysis indicated that in NIV-treated patients that improve their blood gases, mass flow was also redistributed towards areas with higher vessel density and less emphysema, indicating that flow was redistributed towards areas with better perfusion. There was a highly significant correlation between the $\%$ increase in mass flow towards lobes with a blood vessel density of $>9 \%$ and the increase in $\mathrm{PaO}_{2}$. Improved ventilation-perfusion match and recruitment of previously occluded small airways can explain the improvement in blood gases.

Conclusion: We can conclude that in hypercapnic COPD patients treated with long-term NIV over 6 months, a mass flow redistribution occurs, providing a better ventilation-perfusion match and hence better blood gases and lung function. Control patients improve homogeneously in iVaw and iRaw, without improvement in gas exchange since there is no improved ventilation/ perfusion ratio or increased alveolar ventilation. These differences in response can be detected through functional imaging, which gives a more detailed report on regional lung volumes and resistances than classical lung function tests do. Possibly only patients with localized small airway disease are good candidates for long-term NIV treatment. To confirm this and to see if better arterial blood gases also lead to better health related quality of life and longer survival, we have to study a larger population.

Keywords: noninvasive ventilation, COPD, imaging 


\section{Introduction}

COPD is now the fourth leading cause of death in the world. ${ }^{1}$ Patients with severe COPD $\left(\mathrm{FEV}_{1}<50 \%\right)$ often develop chronic hypercapnic respiratory failure. Their prognosis worsens and they are more likely to develop exacerbations. ${ }^{2}$ This has a big influence on their health-related quality of life (HRQOL). ${ }^{3}$

Until now, only few interventions diminish the number of exacerbations and improve survival significantly. Long-acting beta-antagonists and inhaled corticosteroids, as well as pulmonary rehabilitation programs, do influence the number of exacerbations. Long-term oxygen therapy (LTOT) and volume reduction surgery improve survival in well-selected patients. ${ }^{4}$

In hypercapnic patients, noninvasive ventilation (NIV) is often added to the treatment. This can improve gas exchange, unloads the respiratory muscles, and resets the central respiratory drive. It has been shown that NIV in acute settings can prevent intubation and invasive ventilation, and reduces hospital mortality. ${ }^{5,6}$ Nevertheless, there is still little information about NIV given on a long-term basis: it remains unclear how long these patients should be ventilated and what the effect could be. ${ }^{7-11} \mathrm{~A}$ recent study showed that COPD patients who remain hypercapnic after acute respiratory failure requiring mechanical ventilation may benefit from long-term NIV. ${ }^{12}$

Recent randomized studies show a positive effect of longterm (months) ventilation on $\mathrm{CO}_{2}$ retention and HRQOL in stable hypercapnic $\left(\mathrm{PaCO}_{2}>50 \mathrm{mmHg}\right)$ patients on LTOT. ${ }^{2}$ It was also shown that stable, severe chronic hypercapnic patients who were treated with NIV at high inspiratory pressures had a better survival than patients who did not receive NIV: 1- and 2-year survival of $87.7 \%$ and $71.8 \%$ with NIV vs $56.7 \%$ and $42 \%$ without NIV. Patients displaying more severe disease according to known risk factors seemed to benefit most from long-term NIV. ${ }^{13}$ Exercise capacity would improve and intensive care unit admissions would diminish when using chronic NIV with LTOT vs LTOT alone in stable COPD with chronic hypercapnia. All studies took place in patients who were stable at that time.

No information is available about the success of NIV continued at home in patients who needed NIV in an acute setting. In many European countries including Belgium, NIV is not a standard treatment in chronic hypercapnic COPD, and therefore not reimbursed in this case, which is another reason why it is important to prove that chronic NIV can have beneficial effects in hypercapnic COPD.

Until now, only a few outcome parameters have been used in evaluating COPD patients: the measuring of static and dynamic lung volumes and arterial blood gases gives us an idea about the lung as such without regional information. A new method for measuring lung function is functional imaging: with this method regional airway resistance and compliance can be measured by computed tomography (CT)-based computational fluid dynamics (CFD). ${ }^{14-20}$ This method can detect regional differences in both parameters and may reveal still unknown effects of NIV in smaller parts of the lung. The course of the disease may become clearer this way. An improvement in HRQOL can possibly be explained by regional changes in the airways, which can be detected with this method.

Despite lack of evidence, NIV in stable hypercapnic COPD is rated as beneficial and frequently used. ${ }^{21} \mathrm{An}$ explanation for this phenomenon must be looked for.

Is the clue to success the more aggressive form of ventilation as applied by Windisch et al, ${ }^{22}$ where high inspiratory pressures and high breathing frequency are applied in a pressure-controlled methods? It is clear that NIV may improve the alveolar ventilation in a sustained way, since $\mathrm{PaCO}_{2}$ often decreases also during daytime when no NIV is applied. ${ }^{23}$

But perhaps there are just different responder groups among COPD patients. We know that NIV which is insufficient to lower $\mathrm{PaCO}_{2}$ does not improve clinical outcome in stable hypercapnic COPD. And NIV that can improve physiological parameters might have the potential to improve HRQOL and survival.

The aim of this study therefore was to use extended disease descriptors to select and follow hypercapnic COPD patients admitted with acute-on-chronic respiratory failure. Those patients will be treated with supplemental NIV or with routine pharmacological treatment without NIV. We aimed to answer the question: Why is there a decrease of daytime $\mathrm{PaCO}_{2}$ and an increase in daytime $\mathrm{PaO}_{2}$ (and hence an improved HRQOL and survival) only in some COPD patients treated with long-term NIV?

\section{Materials and methods}

Patients after acute hypercapnic COPD exacerbations (treated with NIV in the acute phase) were followed over time in a controlled way using several endpoints. Primary outcome variables were arterial blood gas values and functional imaging of the lungs. Secondary outcome variables were lung function tests (static and dynamic lung volumes, diffusion) and exercise tolerance.

It was a parallel group, randomized, controlled study, prospective with an interventional component (NIV). 
COPD patients GOLD stages III and IV $\left(\mathrm{FEV}_{1}<50 \%\right.$, Tiffeneau $<70 \%$ ) who were hospitalized in the University Hospital of Antwerp (Department of Respiratory Medicine) due to an exacerbation and developed persisting hypercapnia $\left(\mathrm{PaCO}_{2}>45 \mathrm{mmHg}\right.$ ) on days 5-12, despite maximal pharmacological treatment, were randomized into two groups: maximal pharmacological treatment $(n=5)$ vs maximal pharmacological treatment + NIV during 6 months $(n=10)$.

NIV was supplied with a Synchrony BiPAP device (Respironics, Inc, Murrsville, PA), for $>5$ hours a day, with full face mask, starting 5-12 days after admission. Modes were adapted until $\mathrm{O}_{2}$ saturation was $>90 \%$ during $90 \%$ of the time and $\mathrm{PaCO}_{2}$ was decreased $5 \%$ in 1 hour. Patients were ventilated during at least 6 months, and were in follow-up for 1 year.

These patients were re-evaluated at 1,3 , and 6 months by arterial blood gases and pulmonary function tests. CT scan of the thorax was taken at the start of the study and after 6 months. The NIV device was checked and analyzed on every visit. Hospital admissions, morbidity, and mortality were kept in the file.

Patients were included if they were 18-80 years of age, COPD GOLD III or IV ( $\mathrm{FEV}_{1}<50 \%$, Tiffeneau $<70 \%$ ), hospitalized due to an exacerbation, and had persisting hypercapnia $\left(\mathrm{PaCO}_{2}>45 \mathrm{mmHg}\right)$ on day 5-12 under maximal pharmacological treatment. They must have stopped smoking and must not have had any treatment with home NIV before admission. Patients who were invasively ventilated, asthmatic patients, patients with restrictive lung diseases, malignancy, heart failure, or obstructive sleep apnea syndrome were excluded from the study.

All patients underwent a history and physical examination at every visit. Between days 5 and 12, arterial blood gases were taken before starting with NIV. Blood gases were repeated after 1, 3, 6, and 12 months. Between day 5 and 12, lung function tests (spirometry + reversibility, body plethysmography including functional residual capacity (FRC) and airway resistance [Raw], specific airway resistance [sRaw] measurements, diffusion capacity (diffusing capacity of the lung for CO, DCLCO) maximum inspiratory pressure [MIP], maximum expiratory pressure [MEP], 6-minute walking distance $[6 \mathrm{MWD}]$ ) were measured, and were repeated after 1,3 , and 6 months. Also, between day 5 and 12 and repeated after 6 and 12 months, CT scan was performed with a low radiation protocol. These images are made to perform CFD (by FluidDA, Kontich, Belgium) on in order to obtain more information on regional lung function characteristics. Hospital admissions and morbidity/mortality was registered, as well as compliance (memory card Synchrony device and history). The approval of the local ethical committee was obtained.

\section{CT and segmentation ${ }^{14-20}$}

At each CT data collection time point two thorax CT scans were taken on a 64-slice GE LightSpeed VCT scanner. One scan was taken at total lung capacity (TLC), the other at FRC. The lung volumes were controlled during the CT procedure using adapted spirometry. Scans were taken in a dose reduction protocol, ie, reduced tube voltage $(100 \mathrm{kV})$ and tube current as function of the patients' weight (1 mAs $/ \mathrm{kg})$. In addition to this, there was an increase in noise factor to further reduce the radiation dose. Total radiation dose for the CT scans taken in this study per patient was $<12 \mathrm{mSv}$. Scanning time was $<5$ seconds per scan, voxel dimension was $\approx 0.5 \mathrm{~mm}^{3}$, and the scanning region extended from the larynx down to the diaphragm.

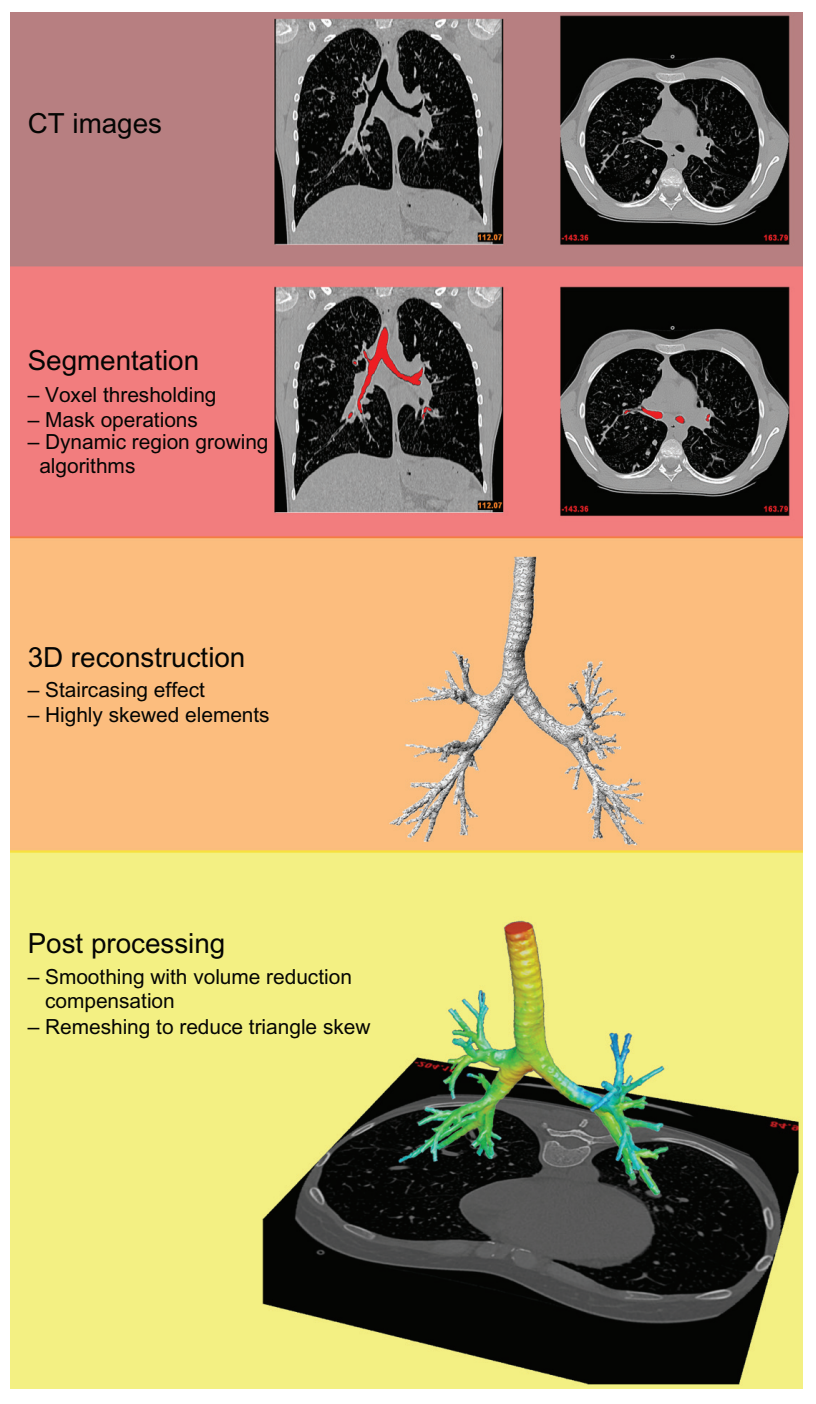

Figure I Functional imaging derived from a high resolution computed tomography scan. 
From the CT data a $3 \mathrm{D}$ reconstruction of the airway geometries at TLC was performed by a semi-automatic segmentation of the airways up to the point where no distinction could be made between the intraluminal and alveolar air (fifth to seventh bifurcation, airway diameter $\approx 1 \mathrm{~mm}$ ). In addition the lung lobes were segmented both at TLC and FRC by identifying the fissure planes and subsequently using these surfaces as cutting objects. By segmenting the lung lobes at two lung levels it was possible to assess the lobar expansion and hence the internal patient specific mass flow distribution in the lower airways. The segmentation and 3D model reconstruction was performed with a commercially developed and validated software package (Mimics, Materialise, Belgium). To determine the local change in airway volume, the models were subdivided in individual branches according to the nomenclature as defined by Ikeda (as described by $\mathrm{Netter}^{24}$ ). For each individual airway branch the airway volume (iVaw) was then determined before and after the study intervention. For each lobe also the volumetric fraction occupied by blood vessels, ie, blood vessel density, was calculated from the CT scan images by taking the percentage of voxels in a lobe that lie in the $[-600$, 600] HU range (Figure 1).

\section{Computational fluid dynamics}

Subsequently the 3D models were converted in a computational grid using a commercial software package (T-Grid, Fluent Inc, USA). Mesh size was around $4.5 \times 10^{6}$ cells. Steady flow simulations on these grids were performed using a commercial CFD solver (Fluent, Fluent Inc, New York, NY). A mass flow of $30 \mathrm{~L} / \mathrm{min}$ was specified as boundary condition at the trachea to reflect normal tidal breathing. At the outlets the static pressure was defined using an iterative process to reflect the internal mass flow distribution matching the lobar expansion as derived from the CT data. The flow was considered laminar, incompressible, and adiabatic. Detailed descriptions of the segmentation and flow simulation procedures can be found in De Backer et al. ${ }^{25}$

From the CFD data the local airway resistance (iRaw) was obtained. iRaw was defined as:

$$
\mathrm{iRaw}=\frac{\Delta p}{F},
$$

where $\Delta p$ equals the total pressure drop over a certain region and $F$ equals the mass flow rate of air through this region.

\section{Statistics}

Variables are presented as mean and standard deviation (SD) for normally distributed variables and as median and range for not normally distributed variables. Differences over time were assessed using Wilcoxon matched pairs test. Correlations were calculated with Spearman correlation analysis. A $P$ value $<0.05$ was considered as statistically significant. All analyses were performed using SPSS 17.0.

\section{Results}

Descriptive data are given in Table 1. Fifteen hypercapnic COPD patients were enrolled, five females and ten males, with a mean age of 65 years and a mean $\mathrm{FEV}_{1}$ of $29 \%$ pred.

Data on blood gases $\left(\mathrm{PaO}_{2}\right)$ and percentage of lobar mass flow and iRaw are given in Figures 2-5 for both groups and individual patients. In both groups there was a nonsignificant change in $\mathrm{FEV}_{1}$ (NIV group 29.5 [standard deviation (SD) \pm 9.0 ] to 38.5 [SD \pm 14.6 ] \%pred; control group $30.5[\mathrm{SD} \pm 5.1]$ to $36.8[\mathrm{SD} \pm 8.7] \mathrm{mmHg}) . \mathrm{PaCO}_{2}$ dropped significantly only in the NIV group (NIV: 55.4

Table I Baseline measurements for all patients enrolled

\begin{tabular}{|c|c|c|c|c|c|c|}
\hline & $\mathbf{N}$ & Range & Minimum & Maximum & Mean & SD \\
\hline Age (years) & 15 & 24 & 52 & 76 & 65.60 & 6854 \\
\hline $\mathrm{PaO}_{2}(\mathrm{mmHg})$ & 15 & 43 & 43 & 86 & 61.73 & 11,298 \\
\hline $\mathrm{PaCO}_{2}(\mathrm{mmHg})$ & 15 & 24 & 45 & 69 & 54.40 & 7169 \\
\hline $\mathrm{FEV}_{1}$ (\%pred) & 15 & 27 & 20 & 47 & 29.80 & 7757 \\
\hline VC (\%pred) & 15 & 65 & 38 & 103 & 64.53 & 15,950 \\
\hline Tiffeneau & 15 & 29 & 23 & 52 & 36.00 & 8358 \\
\hline RV (\%pred) & 15 & 196 & 127 & 323 & 193.47 & $54,|8|$ \\
\hline TLC (\%pred) & 15 & 61 & 90 & $15 \mid$ & 110.80 & 18,899 \\
\hline FRC (\%pred) & 15 & 128 & 121 & 249 & 159.13 & 37,403 \\
\hline Spec R & 15 & 10,600 & 3620 & 14,220 & 6866.87 & 3080.323 \\
\hline DLCO/VA (\%pred) & II & 45 & 42 & 87 & 62.64 & 17.218 \\
\hline MIP (\%pred) & 12 & 77 & 55 & 132 & 77.58 & 22.476 \\
\hline MEP (\%pred) & 12 & 109 & 48 & 157 & 87.17 & 34.803 \\
\hline
\end{tabular}

Abbreviations: VA, alveolar volume; VC, vital capacity; RV, residual volume; TLC, total lung capacity; DLCO, diffusion capacity; MEP, maximum expiratory pressure; MIP, maximum inspiratory pressure; SD, standard deviation. 


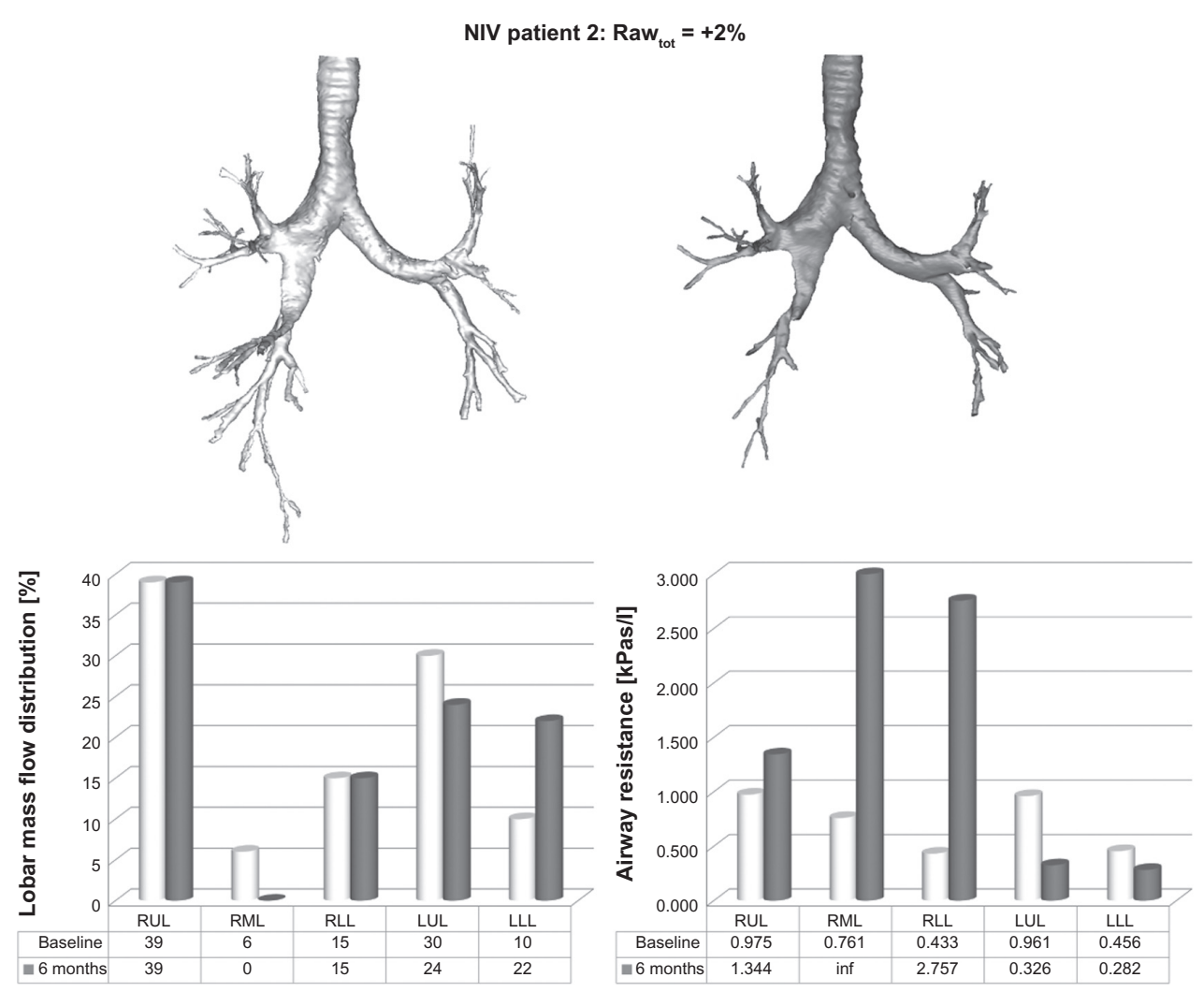

Figure 2 Mass flow (re)distribution (left) and change in airway resistance per lobe (right) in a patient treated with noninvasive ventilation for 6 months. Abbreviations: RUL, right upper lobe; RML, right middle lobe; RLL, right lower lobe; LUL, left upper lobe; LLL, left lower lobe.
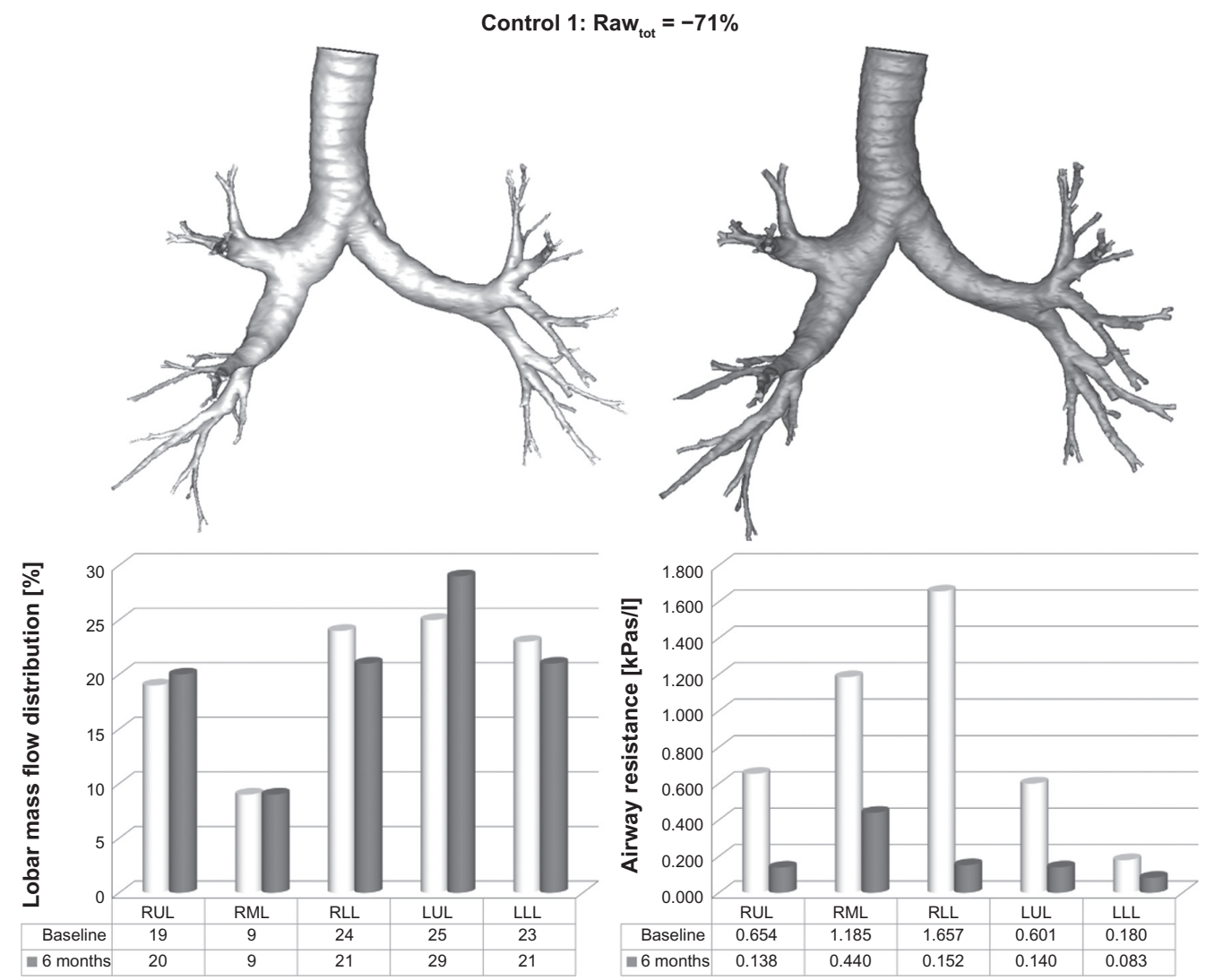

Figure 3 Mass flow (re)distribution (left graph) and change in airway resistance per lobe (right graph) in a patient not treated with noninvasive ventilation for 6 months. Abbreviations: RUL, right upper lobe; RML, right middle lobe; RLL, right lower lobe; LUL, left upper lobe; LLL, left lower lobe. 


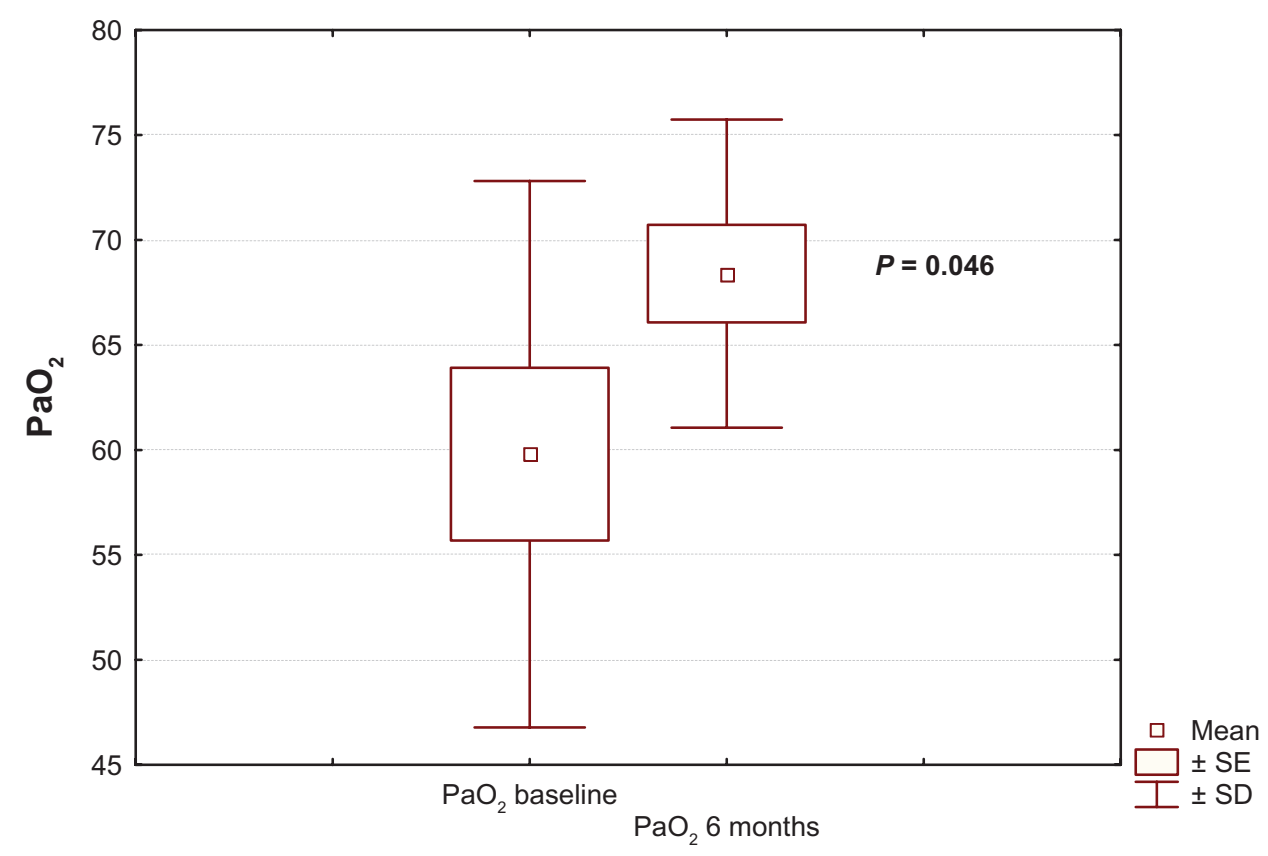

Figure 4 Changes in $\mathrm{PaO}_{2}(\mathrm{mmHg})$ in COPD patients treated with noninvasive ventilation for 6 months. Abbreviations: SE, standard error; SD, standard deviation.

$[\mathrm{SD} \pm 7.7] \rightarrow 44.5[\mathrm{SD} \pm 4.70], P=0.0076$; control group: $52.4[\mathrm{SD} \pm 6.0] \rightarrow 47.6[\mathrm{SD} \pm 8.2], \mathrm{NS})$. The 6-minute walking distance increased significantly in the NIV group $(232 \pm 151 \mathrm{~m}$ to $282 \pm 146 \mathrm{~m}, P=0.01)$, while there was no change in the control group $(408 \pm 34 \mathrm{~m}$ to $401 \pm 78 \mathrm{~m}$, $P=0.085)$. There were no significant changes either in the active or the control group for MIP, MEP, FRC, TLC, Raw, sRaw, and DLCO.
Patients actively treated with NIV developed a more inhomogeneous redistribution of mass flow than control patients (Figure 6). Subsequent analysis indicated that in NIVtreated patients who improved their blood gases, mass flow was redistributed towards areas with higher vessel density and less emphysema, indicating that flow was redistributed towards areas with better perfusion. There was a highly significant correlation between the percentage increase in mass

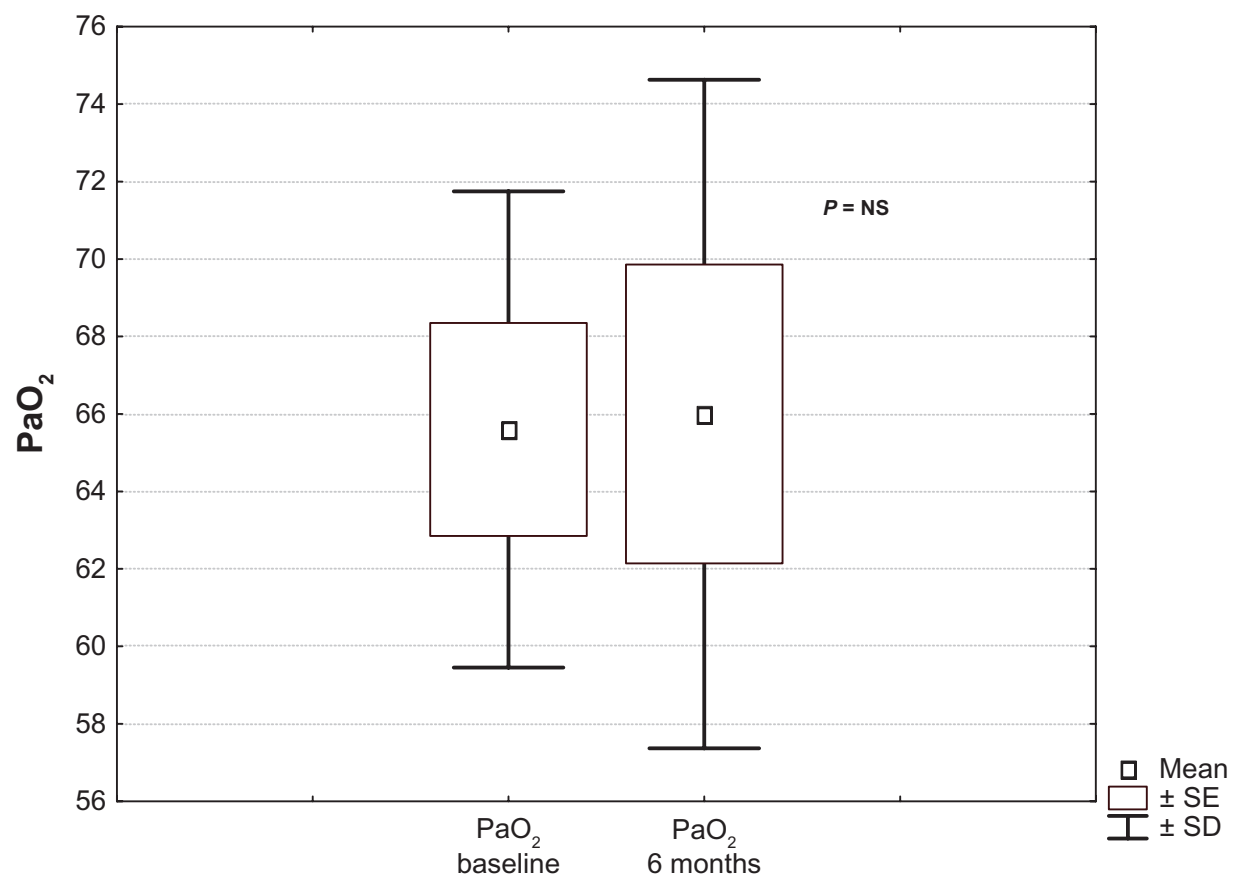

Figure 5 Changes in $\mathrm{PaO}_{2}(\mathrm{mmHg})$ in COPD patients treated without noninvasive ventilation (controls). Abbreviations: SE, standard error; SD, standard deviation; NS, not significant. 


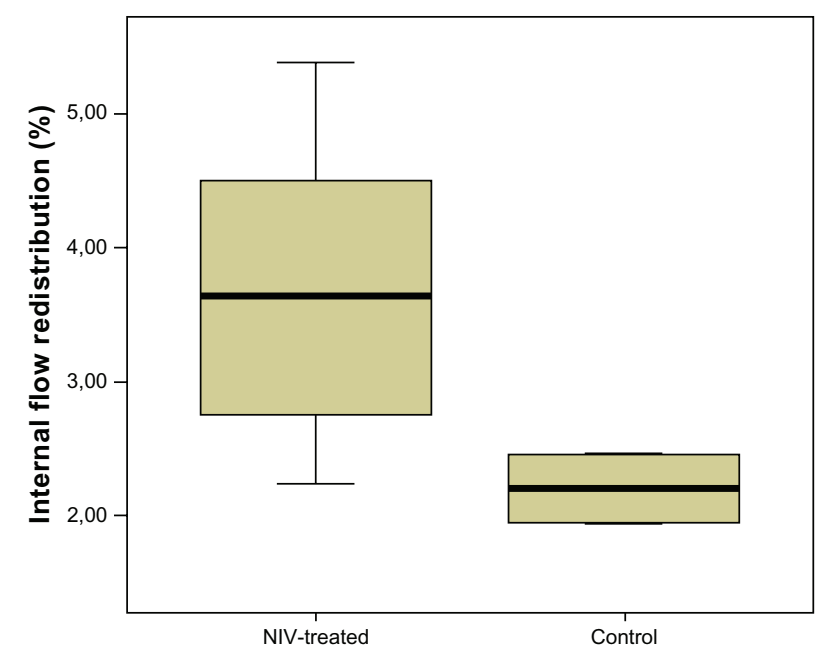

Figure 6 Internal mass flow redistribution was bigger in noninvasive ventilation (NIV)treated patients than in controls.

Notes: Imaging showed higher internal mass flow redistribution in NIV-treated patients: better V/Q matching due to airflow redistribution in NIV-treated patients.

flow towards lobes with a blood vessel density of $>9 \%$ and the increase in $\mathrm{PaO}_{2}$ (Figure 7). This phenomenon can explain the increase in oxygenation seen in the NIV group as a consequence of improved ventilation-perfusion (V/Q) match. The lowering of the $\mathrm{PaCO}_{2}$ in the NIV group $\left(\mathrm{PaCO}_{2}\right.$ at baseline $55.4 \mathrm{mmHg}, \mathrm{PaCO}_{2}$ after 6 months of NIV $44.5 \mathrm{mmHg}$, dif- ference $10.9 \mathrm{mmHg}, P=0.007$ ) can be explained by increased alveolar ventilation by recruitment of the previously occluded peripheral, small airways.

\section{Discussion}

In this study we could observe that COPD patients remaining chronic hypercapnic after an acute exacerbation can be treated effectively with sustained NIV. They can improve their blood gases, both hypoxia and hypercapnia, and we hypothesize that patients with localized emphysema (V/Q mismatch) can achieve this improvement because mass flow is redistributed, with more airflow towards better functioning parts of the lung with preserved blood flow. This then results in a better V/Q match with improved blood gases and improved exercise capacity. We stated that in the past ${ }^{26}$ pulmonary function tests, arterial blood gases, and questionnaires were not able to predict response. Using functional imaging we can predict that there will be a redistribution of mass flow when there are lobes with a blood vessel density $>9 \%$. When air is redistributed towards better functioning lobes, blood gasses $\left(\mathrm{PaO}_{2}\right)$ will improve. This has to be confirmed in a larger population. Patients without lobes with a blood vessel density $>9 \%$ have no chance of redistributing air towards better functioning parts, because there are none. So these are

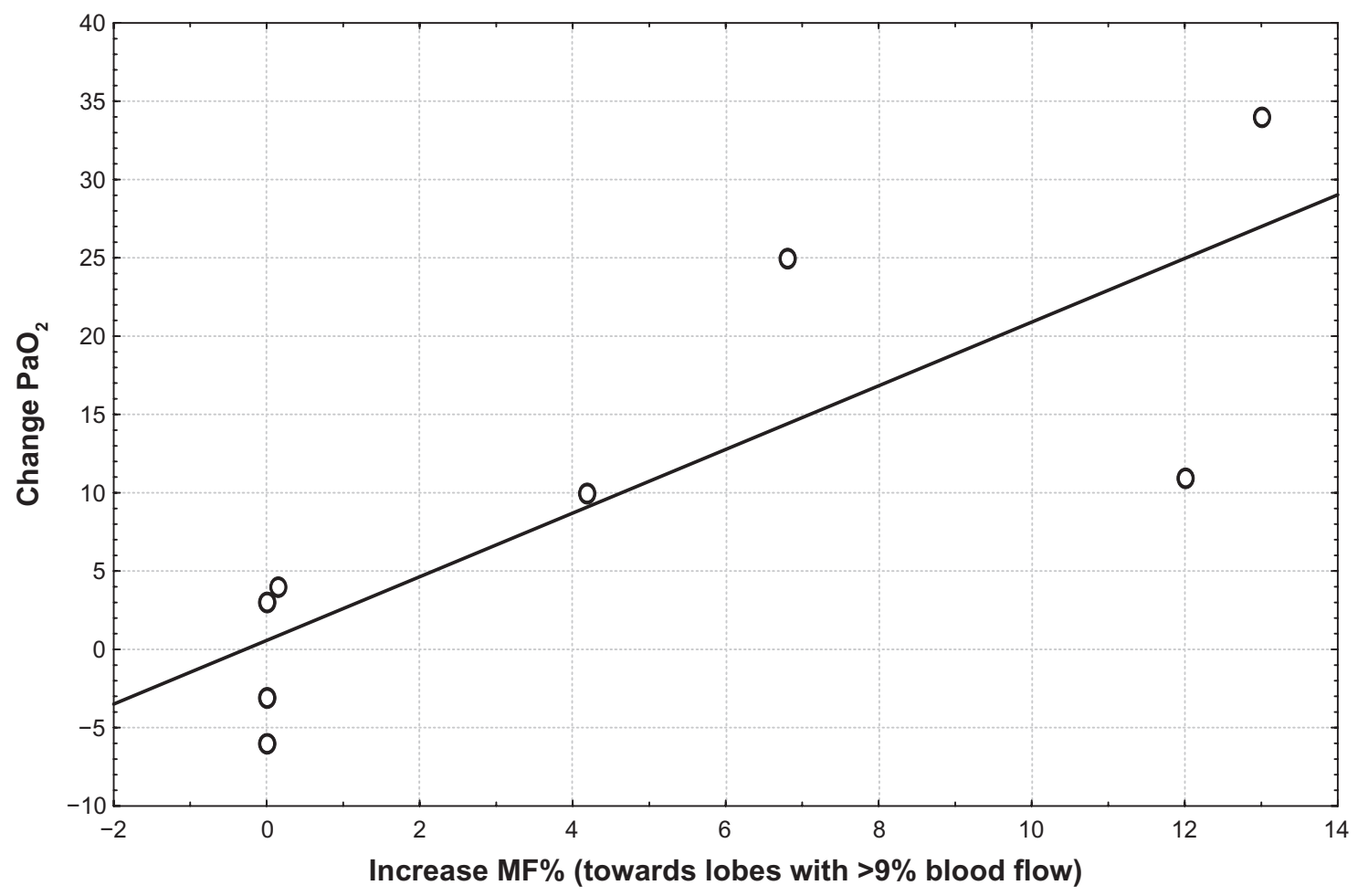

Figure 7 Correlation between redistribution of mass flow towards well-perfused lung zones (>9\% blood flow) and $\mathrm{PaO}$ in $\mathrm{COPD}$ patients treated for 6 months with noninvasive ventilation.

Notes: $r=0.95, P<0.05$ (Spearman Rank).

Abbreviation: MF, mass flow. 
probably worse candidates for long-term NIV. But this also has to be confirmed in a larger population.

Imaging, combined with segmentation (and CFD), shows indeed a remodeling with a redistribution of airflow in some patients, towards better functioning lobes. When we take a closer look and apply CT/CFD to count/calculate the percentage of active blood vessels throughout the different lobes, we can see that air is driven towards lobes with a better V/Q match.

So, from this pilot study, we can suspect that if a stable hypercapnic COPD patient has localized emphysema and still also well-preserved lung areas, the patient is probably a good candidate for long-term NIV.

COPD patients are widely treated with NIV according to the Eurovent study, even without convincing evidence, so there must be some evidence-based arguments for this so far experience-based therapy.

A lot of research has been done in this field with conflicting results. Findings were improvement in arterial blood gases, HRQOL, reduced need for hospitalization, reduced dyspnea, and improvement in exercise capacity. ${ }^{26}$ But these findings were not very consistent and were not confirmed in other studies. A recent large Australian study found improved survival, but poorer general and mental health in NIV-treated patients. ${ }^{27}$

Most studies have focused on clinical outcomes such as improved exercise capacity, ${ }^{28,29}$ and arterial blood gas and lung function tests. ${ }^{22,30}$ Few studies have also focused on HRQOL, ${ }^{31-33}$ which was improved in NIV-treated COPD patients. And in patients with severe disability due to chronic disease, HRQOL may be more important than prolongation of life or improvement in physiologic outcomes.

Conflicting results have been the main findings to date. In stable COPD, NIV does not affect the natural course of the disease ${ }^{34}$. NIV in COPD patients is questionable, controversial, and not definitely proved..$^{35}$ Other factors than those studied until now therefore must play a role in beneficial effects on gas exchange ${ }^{36}$ and it is suspected that there might be a subgroup that responds well to NIV. ${ }^{37}$

To date no real physiological theories have pointed to the mechanism of NIV in COPD. This however is crucial to determine the right endpoints needed to evaluate the treatment in these patients. ${ }^{26}$ Nickol et al ${ }^{38}$ found a higher ventilatory response to $\mathrm{CO}_{2}$ and Diaz et al ${ }^{39}$ explained the success of NIV by less lung hyperinflation and less inspiratory load. Others suggested that the resting of the respiratory muscles causes the effect of NIV. But these hypotheses do not explain the entire mechanism of NIV. Why is it, for example, that higher pressures ${ }^{22,40}$ have better results in COPD patients? There must be a mechanical explanation.

This study started from a different point of view: instead of focusing primarily on clinical outcome, the focus was on a possible mechanism for explaining the treatment, which makes treatment modes and candidates easier to find, because of the physiological foundation.

By studying the different parts of the lungs, regional effects and shifts of mass flow become clear. Previous techniques, such as classical lung function tests and arterial blood gases, give some idea about the lungs as a whole, but no differences can be detected between the effects on different parts of the lung. Functional imaging is the first technique to do so. This is the reason why these mechanisms were not discovered before, and could be a clue about the effect of NIV in COPD.

It seems that there is a mechanical effect of blowing air into the lungs over a longer period and that airway recruitment takes place with a beneficial outcome. After a certain period (we do not know for how long, but definitely after 6 months) air goes to better perfused areas, resulting in more efficient gas exchange.

From the results of this study, we can conclude that pulmonary function tests and arterial blood gases, were not enough to predict which patients are the right candidates for the treatment.

We looked at airway and lobe specifics with a new technology that makes it possible to calculate regional differences in airway volume, lobe volume, and airway resistance. With this method, we can look at each airway and each lobe separately.

The study could be criticized for starting treatment at the end of an exacerbation and comparing an outcome a few months later in a stable situation. However, we studied a real life situation, which is more useful for application to clinical practice. One week after the start of the exacerbation, lung function tests and arterial blood gasses can reach a less critical level, what makes it reasonable to start from this point. In real life it is also exactly at this point that the physician has to decide whether or not to continue NIV at home. Because of the small sample size, randomization cannot guarantee the balance of the distribution of confounders between the two groups.

We can conclude from these study results that chronic hypercapnic COPD patients who respond to long-term NIV have the capability to recruit peripheral airways and increase their alveolar ventilation in well-preserved lung zones in a sustained way. It remains to be determined 
whether this recruitment occurs very early in the course of the NIV treatment and whether early evaluation of the flow redistribution can help us to select the patients who merit continued treatment. The overall response to NIV was good, but when we look at each patient separately, we can see that the response can be worse according to our hypothesis: less localized emphysema gives less possibility for improving V/Q mismatch and arterial blood gasses.

Finally the relationship between the level of applied (inspiratory) pressure and the peripheral/small airway recruitment is yet to be determined, as is the sustainability of the obtained changes after interruption of NIV treatment. So although many more questions have to be answered, the method we used in this preliminary study can further be used in studies addressing these remaining questions.

\section{Disclosure}

The authors declare no conflicts of interest in relation to this paper.

\section{References}

1. Pauwels RA, Rabe KF. Burden and clinical features of chronic obstructive pulmonary disease (COPD). Lancet. 2004;364(9434):613-620.

2. Clini E, Sturani C, Rossi A, et al. The Italian multicentre study on noninvasive ventilation in chronic obstructive pulmonary disease patients. Eur Respir J. 2002;20(3):529-538.

3. Seemungal TA, Hurst JR, Wedzicha JA. Exacerbation rate, health status and mortality in COPD - a review of potential interventions. Int J Chron Obstruct Pulmon Dis. 2009;4:203-223.

4. Calverley PM. Closing the NETT on lung volume reduction surgery. Thorax. 2003;58(8):651-653.

5. Rasche K, Hader C, Leidag M, Duchna HW, Orth M. Non-invasive ventilation in chronic obstructive pulmonary disease. $J$ Physiol Pharmacol. 2004;55 Suppl 3:115-119.

6. Plant PK, Elliott MW. Chronic obstructive pulmonary disease * 9: management of ventilatory failure in COPD. Thorax. 2003;58(6): 537-542.

7. Chu CM, Chan VL, Lin AW, Wong IW, Leung WS, Lai CK. Readmission rates and life threatening events in COPD survivors treated with non-invasive ventilation for acute hypercapnic respiratory failure. Thorax. 2004;59(12):1020-1025.

8. Tuggey JM, Plant PK, Elliott MW. Domiciliary non-invasive ventilation for recurrent acidotic exacerbations of COPD: an economic analysis. Thorax. 2003;58(10):867-871.

9. Quinnell TG, Pilsworth S, Shneerson JM, Smith IE. Prolonged invasive ventilation following acute ventilatory failure in COPD: weaning results, survival, and the role of noninvasive ventilation. Chest. 2006; 129(1):133-139.

10. Simonds AK. Home ventilation. Eur Respir J Suppl. 2003;47: $38 \mathrm{~s}-46 \mathrm{~s}$.

11. Simonds AK. Long-term ventilation in obstructive ventilatory disorders. Respir Care Clin N Am. 2002;8(4):533-544.

12. Funk GC, Breyer MK, Burghuber OC, et al. Long-term non-invasive ventilation in COPD after acute-on-chronic respiratory failure. Respir Med. 2011;105(3):427-434.

13. Budweiser S, Hitzl AP, Jorres RA, et al. Impact of noninvasive home ventilation on long-term survival in chronic hypercapnic COPD: a prospective observational study. Int J Clin Pract. 2007;61(9): 1516-1522.
14. De Backer JW, Vos WG, Vinchurkar SC, et al. Validation of computational fluid dynamics in CT-based airway models with SPECT/CT. Radiology. 2010;257(3):854-862.

15. De Backer JW, Vos WG, Burnell P, et al. Study of the variability in upper and lower airway morphology in Sprague-Dawley rats using modern micro-CT scan-based segmentation techniques. Anat Rec (Hoboken). 2009;292(5):720-727.

16. De Backer JW, Vos WG, Gorle CD, et al. Flow analyses in the lower airways: patient-specific model and boundary conditions. Med Eng Phys. 2008;30(7):872-879.

17. De Backer JW, Vos WG, Devolder A, et al. Computational fluid dynamics can detect changes in airway resistance in asthmatics after acute bronchodilation. J Biomech. 2008;41(1):106-113.

18. De Backer JW, Vanderveken OM, Vos WG, et al. Functional imaging using computational fluid dynamics to predict treatment success of mandibular advancement devices in sleep-disordered breathing. J Biomech. 2007;40(16):3708-3714.

19. Van HC, De BJ, Vos W, et al. Anatomical and functional changes in the upper airways of sleep apnea patients due to mandibular repositioning: a large scale study. J Biomech. 2011;44(3):442-449.

20. Vos W, De BJ, Devolder A, et al. Correlation between severity of sleep apnea and upper airway morphology based on advanced anatomical and functional imaging. J Biomech. 2007;40(10):2207-2213.

21. Lloyd-Owen SJ, Donaldson GC, Ambrosino N, et al. Patterns of home mechanical ventilation use in Europe: results from the Eurovent survey. Eur Respir J. 2005;25(6):1025-1031.

22. Windisch W, Haenel M, Storre JH, Dreher M. High-intensity noninvasive positive pressure ventilation for stable hypercapnic COPD. Int J Med Sci. 2009;6(2):72-76.

23. Wijkstra PJ, Lacasse Y, Guyatt GH, et al. A meta-analysis of nocturnal noninvasive positive pressure ventilation in patients with stable COPD. Chest. 2003;124(1):337-343.

24. Netter FH. The Ciba Collection of Medical Illustrations, Vol 7: Respiratory System. Summit, NJ: CIBA; 1979.

25. De Backer JW, Vos WG, Gorle CD, et al. Flow analyses in the lower airways: patient-specific model and boundary conditions. Med Eng Phys. 2008;30(7):872-879.

26. Elliott MW. Domiciliary non-invasive ventilation in stable COPD? Thorax. 2009;64(7):553-556.

27. McEvoy RD, Pierce RJ, Hillman D, et al. Nocturnal non-invasive nasal ventilation in stable hypercapnic COPD: a randomised controlled trial. Thorax. 2009;64(7):561-566.

28. Borghi-Silva A, Mendes RG, Toledo AC, et al. Adjuncts to physical training of patients with severe COPD: oxygen or noninvasive ventilation? Respir Care. 2010;55(7):885-894.

29. Wijkstra PJ, Wempe JB, van der Bij W, Klinkenberg T, ten Hacken NH, Koeter GH. Improved exercise tolerance can be achieved in chronic obstructive pulmonary disease (COPD) by means of non-pharmacological treatment. Ned Tijdschr Geneeskd. 2006;150(22):1213-1217. Dutch.

30. Diaz O, Begin P, Andresen M, et al. Physiological and clinical effects of diurnal noninvasive ventilation in hypercapnic COPD. Eur Respir J. 2005;26(6):1016-1023.

31. Clini EM, Magni G, Crisafulli E, Viaggi S, Ambrosino N. Home non-invasive mechanical ventilation and long-term oxygen therapy in stable hypercapnic chronic obstructive pulmonary disease patients: comparison of costs. Respiration. 2009;77(1):44-50.

32. Tsolaki V, Pastaka C, Kostikas K, et al. Noninvasive ventilation in chronic respiratory failure: effects on quality of life. Respiration. 2010.

33. Duiverman ML, Wempe JB, Bladder G, et al. Nocturnal non-invasive ventilation in addition to rehabilitation in hypercapnic patients with COPD. Thorax. 2008;63(12):1052-1057.

34. Casanova C, Celli BR, Tost L, et al. Long-term controlled trial of nocturnal nasal positive pressure ventilation in patients with severe COPD. Chest. 2000;118(6):1582-1590.

35. Rossi AG. Inflammation. 2003-Sixth World Congress. Focus on chronic obstructive pulmonary disease. August 2-6, 2003, Vancouver, Canada. IDrugs. 2003;6(9):838-840. 
36. Krachman SL, Criner GJ. Sleep and long-term ventilation. Respir Care Clin N Am. 2002;8(4):611-629.

37. Hill NS. Noninvasive ventilation for chronic obstructive pulmonary disease. Respir Care. 2004;49(1):72-87.

38. Nickol AH, Hart N, Hopkinson NS, et al. Mechanisms of improvement of respiratory failure in patients with COPD treated with NIV. Int $J$ Chron Obstruct Pulmon Dis. 2008;3(3):453-462.
39. Diaz O, Begin P, Torrealba B, Jover E, Lisboa C. Effects of noninvasive ventilation on lung hyperinflation in stable hypercapnic COPD. Eur Respir J. 2002;20(6):1490-1498.

40. Dreher M, Storre JH, Schmoor C, Windisch W. High-intensity versus low-intensity non-invasive ventilation in patients with stable hypercapnic COPD: a randomised crossover trial. Thorax. 2010;65(4):303-308.

\section{Publish your work in this journal}

The International Journal of COPD is an international, peer-reviewed journal of therapeutics and pharmacology focusing on concise rapid reporting of clinical studies and reviews in COPD. Special focus is given to the pathophysiological processes underlying the disease, intervention programs, patient focused education, and self management protocols.
Dovepress

This journal is indexed on PubMed Central, MedLine and CAS. The manuscript management system is completely online and includes a very quick and fair peer-review system, which is all easy to use. Visit $\mathrm{http} / / / \mathrm{www}$.dovepress.com/testimonials.php to read real quotes from published authors.

Submit your manuscript here: http://www.dovepress.com/international-journal-of-copd-journal 